\title{
Uncommon localisation of Ofuji disease in a Moroccan patient
}

\author{
Sanae Sialiti, Mehdi Khallaayoune, Mariame Meziane, Karima Senouci
}

Dermatology-Venerology Department, Mohammed V University of Rabat, Rabat, Morocco

\section{Correspondence to}

Dr Mehdi Khallaayoune; khallaayounemehdi@gmail.com

Accepted 26 March 2021

\section{DESCRIPTION}

A Moroccan 18-year-old patient with a history of left mastectomy because of naevoid keratosis of the nipple arrived presenting pruritic papulopustular lesions located on the surgical scar as well as his extremities, without any associated systemic signs.

The lesions showed resistance to local antifungals, and examination revealed the presence of follicular papulopustular lesions, with a centrifugal evolution in many sites: the upper and lower limbs, the left flank, and the mastectomy scar, where the lesions seemed severely infiltrated (figure 1).

Laboratory investigation revealed the following: an absolute eosinophilia $(950 / \mu \mathrm{L})$, sterile bacteriological and mycological specimens, a negative retroviral serology and a total immunoglobulin $\mathrm{E}$ that was slightly elevated.

Histopathology revealed spongiosis and dense eosinophilic perifollicular inflammatory infiltrate (figure 2).

Based on these results, the diagnosis of eosinophilic pustular folliculitis (EPF) was established.

The decision taken was to administer $100 \mathrm{mg} /$ day of dapsone to the patient, taking into account his allergy to non-steroidal anti-inflammatory drugs (NSAIDs). Following this, lesions totally improved. The healing of the surgical scar was 3 months delayed.

EPF also known as Ofuji disease is a rare inflammatory dermatitis, with unknown aetiology, first reported in the Japanese population with a male predominance.

It is characterised by a non-infectious inflammation of the pilosebaceous follicles, and is caused by an eosinophil infiltration. It is associated with aseptic pruritic papulopustular lesions of circular configuration, located on the face, back and chest, which all correspond to seborrheic areas. ${ }^{1}$

Concerning the clinical variants, there are three of them: (1) classic EPF, corresponding to Ofuji disease observed on male Asian patients; (2) immunosuppression-associated EPF (mostly

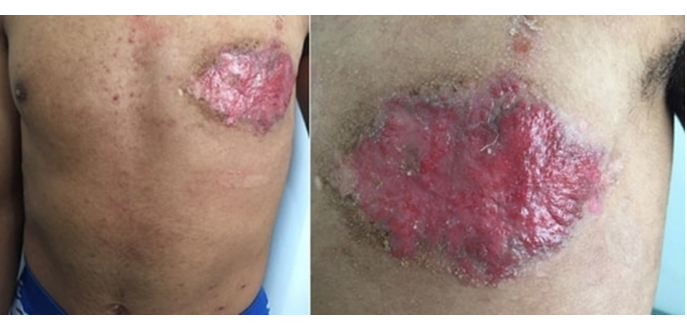

Figure 1 Erythematous and crusted papulopustules on the left mastectomy scar.

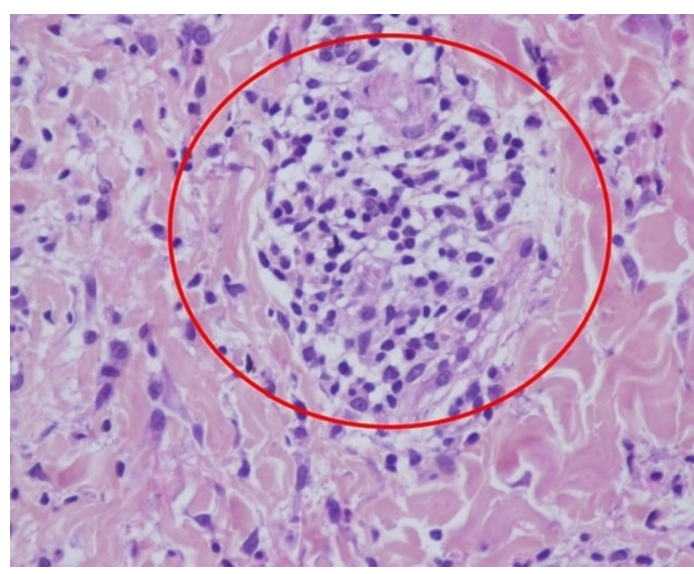

Figure 2 Histological section showing spongiosis, associated with an inflammatory eosinophilic perifollicular infiltrate (red circle) without signs of vasculitis.

HIV-associated EPF, malignant haemopathies and organ transplant) and (3) an observed form on children, characterised by papulopustular lesions surmounted by crusts, extremely itchy and mainly spreading on the scalp. ${ }^{2}$

Histopathology is of crucial value for diagnosis confirmation, describing infundibular spongiosis, dermal infiltration of inflammatory cells with perifollicular and perivascular eosinophils, and some neutrophils and mononuclear cells.

Occasionally, additional histological results are observed, such as focal destruction of the outer follicular sheath; neutrophil and basophil infiltration may also be reported, while $\mathrm{CD} 8^{+}$lymphocytes are most frequently seen in the HIV-associated type. $^{3}$

This being said, this pathophysiology remains unknown. Some assumptions suggest a hypersensitivity to the medication or an immunological alteration leading to an increased secretion of eosinophils. Prostaglandin D2 (PGD2) appears to be involved in the pathogenesis of EPF. It causes sebocytes to produce eotaxin-3, which is a chemoattractant for eosinophils by producing interleukin-5, thus leading to the formation of massive infiltrates of eosinophils around pilosebaceous units. ${ }^{4}$

In the case of our patient, a Koebner phenomenon could be incriminated for maintaining these lesions on the mastectomy scar.

Clinical differential diagnoses include infectious diseases such tinea faciei, inflammatory diseases like acne, rosacea, lupus miliaris disseminatus faciei and even a folliculotropic mycosis fungoides, a rare variant of cutaneous $\mathrm{T}$ cell lymphoma. ${ }^{3}$ 
Several treatments might be suggested to the patient, including corticosteroids, retinoids, dapsone, colchicine, cyclosporine and minocycline. However, indomethacin remains the most effective treatment so far. In case of allergy to NSAIDs (as for our patient), dapsone presents a good alternative, with positive feedback on its effectiveness from several teams. ${ }^{5}$

However, a notable element would be that the old scars' resistance could be explained by the presence of a deeper eosinophilic infiltration due to the alteration of the skin surface.

\section{Learning points}

Ofuji's eosinophilic folliculitis is a rare entity that can mime several dermatosis.

- The occurrence of eosinophilic folliculitis on a scar should suggest the hypothesis of a Koebner phenomenon, so far not described.

- An early and well-conducted treatment allows a total healing of the lesions without notable complications.
Contributors SS: took care of the patient and wrote the article. MK: collaborated in the care of the patient and the design of the article. MM: is responsible for the consultations and therapeutic decisions of the patient and contributed in the design and execution of the paper. KS: is responsible for all professional and scientific activities.

Funding The authors have not declared a specific grant for this research from any funding agency in the public, commercial or not-for-profit sectors.

Competing interests None declared.

Patient consent for publication Obtained.

Provenance and peer review Not commissioned; externally peer reviewed.

\section{REFERENCES}

1 Nervi SJ, Schwartz RA, Dmochowski M. Eosinophilic pustular folliculitis: a 40 year retrospect. J Am Acad Dermatol 2006;55:285-9.

2 Anjaneyan G, Manne S, Panicker VV, et al. Ofuji's disease in an immunocompetent patient successfully treated with dapsone. Indian Dermatol Online J 2016;7:399.

3 Fujiyama T, Tokura Y, Toshiharu F. Clinical and histopathological differential diagnosis of eosinophilic pustular folliculitis. J Dermatol 2013;40:419-23.

4 Nakahigashi K, Doi H, Otsuka A, et al. Pgd2 induces eotaxin-3 via PPARy from sebocytes: a possible pathogenesis of eosinophilic pustular folliculitis. J Allergy Clin Immunol 2012;129:536-43.

5 Ellis E, Scheinfeld N. Eosinophilic pustular folliculitis: a comprehensive review of treatment options. Am J Clin Dermatol 2004;5:189-97.

Copyright 2021 BMJ Publishing Group. All rights reserved. For permission to reuse any of this content visit

https://www.bmj.com/company/products-services/rights-and-licensing/permissions/

BMJ Case Report Fellows may re-use this article for personal use and teaching without any further permission.

Become a Fellow of BMJ Case Reports today and you can:

- Submit as many cases as you like

- Enjoy fast sympathetic peer review and rapid publication of accepted articles

- Access all the published articles

Re-use any of the published material for personal use and teaching without further permission

Customer Service

If you have any further queries about your subscription, please contact our customer services team on +44 (0) 2071111105 or via email at support@bmj.com.

Visit casereports.bmj.com for more articles like this and to become a Fellow 